\title{
Sustainability in the Meat Processing Industry and the Impact of the COVID-19 Crisis on the Food Business in Romania
}

\author{
Elena Radu ${ }^{1}$, Claudiu Nicolae Ghinea ${ }^{2}$, Ștefan Mihalache ${ }^{3}$ and Roxana Sârbu ${ }^{4}$ \\ 1)3)4) The Bucharest University of Economic Studies, Romania \\ 2) Therme Media \\ E-mail: elena.radu2102@gmail.com; E-mail: claudiung95@yahoo.com \\ Email: stefan_mihalache03@yahoo.com; E-mail: sarbu.roxana@ase.ro
}

\begin{abstract}
Please cite this paper as:
Radu, E., Ghinea, C.N, Mihalache, Ș. and Sârbu, R., 2021. Sustainability

in the Meat Processing Industry and the Impact of the CovID-19 Crisis on the Food Business in Romania.. 7th BASIQ International Conference on New Trends in Sustainable Business and Consumption. Foggia, Italy, 3-5 June 2021. Bucharest: ASE, pp. 425-430 DOI: 10.24818/BASIQ/2021/07/055
\end{abstract}

\begin{abstract}
In a world with a growing population, a health crisis, global warming and limited resources, the global community is increasingly involved in finding innovative solutions to long-term sustainable consumption patterns. Consumers are more aware that the purchases they make should support sustainability goals and are even more willing to pay more for products that contain sustainable, organic or natural ingredients. Food manufacturers around the world have responded to these changing demands by developing and launching a growing number of products that claim to be "environmentally friendly". Despite the crisis caused by Covid-19, the main purpose remaining to protect the environment.

In this paper, we want to analyze how the food industry reacted to the crisis generated by the SARSCOV-2 virus, and for this we made a portrait before and after the crisis, describing how the food industry has adapted to the change generated by this virus, using the observation method.
\end{abstract}

\section{Keywords}

Sustainability, food industry, Covid-19, meat industry, crisis, consumer/customer, supply chain.

DOI: 10.24818/BASIQ/2021/07/055

\section{Introduction}

The great confinement encouraged accelerated experimentation with new organizational practices. The impacts of the health crisis were very strong, from March 2020 during the time of confinement and then in the time of deconfinement from May 11 and the recovery after June 24, in terms of collective commitment and individual, adaptation, health, very rapid adoption of new working methods.

Businesses have been challenged to adjust very quickly to deal with the emergency. With the interconnection of crises - health, economic, social, environmental - the situation has changed and all stakeholders must question the lasting impacts of this experience, which is as unique as it is intense.

The crisis has revalued the role of proximity and committed organizations to a greater humanization of management, with new forms of organization of work and life at work, and a more concerned raison d'être and economic model of nature, gender and social equity to respond to the strengthening of several major societal trends (Peretti, 2020). The experience of those weeks when the economy came to a screeching halt and in the period of recovery should be a source of reflection and teaching for researchers and policy makers. 
In the paper "Changement de crise, les organisations, à l'épreuve du COVID-19" (Peretti, Autissier, Besseyre des Horts, 2020), a group of management professionals and researchers proposed a first formalization which aims to understand the way in which the crisis was experienced in private and public organizations and also to highlight good practices likely to be perpetuated. The testimonies and reflections of 30 co-authors living in countries with different contexts (China, Korea, France, India, Quebec, Senegal, Tunisia) on the situation of organizations during the Covid-19 crisis describe how organizations have adapted, the difficulties encountered, the innovations that emerge and the major management issues that arise with the crisis. In crisis trajectory: adaptation of organizations to the crises of Covid19 (Autissier, Besseyre des Horts et Peretti, 2020), the co-authors wonder about what will change based on the experiments experienced in the trajectory crises, this succession of interconnected periods of health, economic, social and societal crises. To fuel the debate on the lessons to be drawn from this experience during a first half of 2020 deeply disturbed by the crisis experienced by organizations and on the lasting impacts on the managerial level, Question (s) de management questioned in June $2020 \mathrm{a}$ new panel of actors committed to their vision of the world after asking them to answer a crucial question in this period of recovery: "What are the organizational changes brought about by the Covid-19 crisis?"

With the development of the COVID-19 pandemic, many countries have expressed concern about food security. Although the crisis has had a direct impact on the food and agricultural supply chain, the negative impact of the COVID-19 pandemic is not limited to short-term supply and demand disruptions. Although these disruptions have had serious negative effects, they have also accelerated the industry's need to adapt. The most important of these trends is digitalization and changing consumer preferences. These accelerators provide opportunities for longer-lasting recovery. However, all participants in the agri-food value chain need to prepare for the larger structural changes that will affect the sector, including climate change and stricter environmental legislation. To some extent, the pandemic is the preamble to these changes.

\section{The agro-food industry in Romania before The Covid-19 pandemic period}

According to the words reported in Romania's National Sustainable Development Strategy 2030, adopted by the Romanian Government, in 2018 and 2019, Romania's GDP increased by around 4\%. The growth is attributed to Romania's strategic location, increasing consumer demand and an improved business climate. Agriculture plays an important role in the economy. There are almost 4 million farms in the country, which is one third of all farms in the European Union. Moreover, unlike most of the region, the agricultural sector in Romania has a suitable job offer.

Thanks to the position on the map, it also has sufficient water and land resources. Romania's agricultural sector accounts for the largest proportion of total employment in Central and Eastern European countries (so far-about 15 percentage points higher than the 2017 European Economic Community average). However, this share has steadily declined from approximately $33 \%$ in 2005 to approximately $23 \%$ in 2017 . In the past 10 years, the value of agricultural production has increased significantly in all sectors. The structure of Romania's agriculture is as follows: vegetable production accounts for approximately $66 \%$, animal production accounts for approximately $25 \%$, processing accounts for approximately $8 \%$, and the last $1 \%$ represents agricultural service production.

This suggests that Romania may be more vulnerable than other CEE countries to changes in demand for high added value goods. The main sub-sectors of the Romanian food and processing category are: meat, dairy products, fish products, fruits and vegetables (in the form of jam, jam and canned vegetables) and bread.

According to USDA FAS data, Romania's "natural" and organic products are still subject to certain restrictions. The local food processing industry has not yet committed to developing these market areas because the consumer base for these products must continue to maintain high incomes. Local suppliers of organic products that can be consumed in Romania are still limited, and the prices of these products are high. Romania has a long tradition of eating processed meat and seafood. These products are still very popular and are becoming more and more "advanced". More and more products come from seafood, chicken, turkey, goose and duck. 
Manufacturers also promote these products in healthier markets (for example, no artificial ingredients, etc.). Before the pandemic, people's overcrowding of lifestyles and interest in healthy products were expected to result in a steady increase in the demand for healthy products, including such organic products. According to the latest available data, Romania's retail market was worth 37.2 billion euros in 2018, with 2500 companies. For retailers, online shopping is seen as a possible area for expansion, with only $8 \%$ of Romanian households ordering online.

\section{How the meat processing industry was affected}

The high rates of Covid-19 contamination in slaughterhouses and meat processing plants all over the world have put the spotlight on the failures of this model. In France, Germany, Australia, the United State. All countries have been affected by this phenomenon. Few studies make it possible to understand why these places have become nests for Covid-19, but several hypotheses have been put forward such as the strong promiscuity between the workers, the humidity of the places, the ventilation systems, the poor social protection of the employees who were there, or going to work despite potential symptoms.

Pressure has been mounting since March 2020, when measures to spread the SARS COV-2 virus taken by all countries have hampered and blocked imports and exports.

Being faced with such a situation, companies began to increase their stocks, to make supplies of raw materials. There was also a lot of pressure from the behaviour of customers who rushed to the stores to create supplies. Merchants did not think that customers would no longer visit stores, but that they would have nothing to offer customers (Hobbs, 2021).

The meat industry subsectors that have been affected are: Meat Processing (Abattoirs), Wholesaling and Retailing of meat products, Poultry Processing.

The meat processing companies that represented an advantage during this period were the highly technological companies, which depended as little as possible on the work of the individual. I must remember that this industry cannot function with the help of telework.

At the organizational level, meat processing units and slaughterhouses have resorted to a series of measures both to limit the occurrence of an outbreak at work, but also for consumer health.

As an example, some controls, in the United States of America, were based on honest and open communication with employees. This means meat companies have established a clear test, contact tracing, and isolation plan based on guidelines issued by the Centers for Disease Control and Prevention from United States of America. The meat companies made this information available to their workers in their language and community. This communication, combined with effective liaison with local public health departments, has allowed workers to understand the risk of infection and the steps everyone should take to stay safe. It appears that this communication effort to build workers' confidence in work safety was a key element, not only for maintaining a sufficient number of employees, but also for ensuring that surveillance and prevention strategies were followed.

According to the Centers for Disease Control and Prevention, almost all meat factories carry out daily temperature checks on all workers and visitors before entering the factories. In addition, visits inside the factory are limited to unnecessary visitors. This has always been the basis of the surveillance process and has worked closely with doctors and local public health authorities to provide an appropriate analysis. The purpose of this strategy is to eliminate the entry of infected people, which will create the potential for the virus to spread to the workplace.

Detection of infection among employees has been widely used and has generally been successful. In some factories, all workers have been tested. Many of these tests are performed by private laboratories with very fast response times, so employees can be notified, contacts can be quickly tracked, and follow-up tests are performed to ensure that the infection does not spread. Observed results indicate that the widespread implementation of exposure testing and subsequent quarantine and other prevention strategies actually prevented transmission to the workplace.

In meat factories, great efforts have been made to prevent the spread of aerosols or objects. For all employees, it has become common practice to wear masks in certain places unless they eat. Once again, 
anecdotal observations seem to indicate that the use of masks in meat factories, combined with testing, is very successful in eliminating transmission to the workplace (Barbut, 2020).

In addition, some factories have implemented face masks to prevent contact of the drops of saliva with the nose and eyes, although their use is not as common as the use of masks, and their effects have not been scientifically evaluated.

These facilities have increased the number of personnel dedicated to cleaning and disinfecting all public areas, greatly improving internal hygiene. In Romania, the law stipulates that the production areas of the meat industry must be thoroughly cleaned and disinfected every day. Historically speaking, this was designed with food safety in mind, but it also moved SARS-CoV2 away from work and contact areas. Many factories have implemented better cleaning in public areas such as dining rooms, laundry rooms, toilets, halls and attendance control clocks, at least three times per shift. Use food-safe disinfectants and cleaners for cleaning. These disinfectants and cleaners have proven effective against SARS-CoV2. The type of product is not as important as frequent and thorough cleaning: all ordinary surfaces must be cleaned to remove dust and debris, and then these surfaces must be disinfected. Many meat processing plants work hard to eliminate points of contact to minimize the frequency of worker interaction.

Separators are installed on all tables in the canteen. Masks cannot be used during meals. These partitions ensure that workers can stand independently. These spacers are usually made of clear crylic resin and rise more than $0.9 \mathrm{~m}$ above the table to prevent airborne transmission.

The factory has developed a system to ensure the cleanliness of the chairs in the restaurant, usually using a red / green card: after the employee uses the chair, it is placed on the red side, indicating that it should be disinfected before the next use. The installation of these separators at lunch can minimize the mass transmission of aerosols.

Other measures taken were: opening the doors so as not to touch the surfaces, dispersing the equipment, installing separators between the places on the belt.

\section{Improving sustainability in the meat processing industry}

Sustainability in terms of the use of resources and the use of energy efficient processes along the value chain is one of the greatest challenges of our time. And this also applies to the meat processing industry. Intelligent control and automation technology, energy efficient drive systems, compressors, fans and pumps are among the classic solutions to improve energy efficiency and resource efficiency.

An uninterrupted and efficient cold chain is the number one priority for food safety in the meat processing industry. Refrigeration, icing and freezing are the most important processes to prevent highly perishable products, such as meat and sausage products, from spoiling. Therefore, the demands placed on modern refrigeration installations, such as cold chillers, cold and cold stores, cooling tunnels, spiral, plate and helical band glazing systems are increasing rapidly. However, cooling is one of the most complex processes in terms of energy. According to official estimates, refrigeration accounts for around $30 \%$ of total electricity consumption. In many cases, cooling equipment is not perfectly matched to actual needs, resulting in lower efficiency levels and higher energy costs. Modernizing the existing cooling installation and adapting it to current needs is an economic and ecological way to increase efficiency, for example by reconditioning the compressor, optimizing the liquefier or adapting a heat recovery system.

In addition to producing coolants, providing heat is also an energy-intensive and expensive process in the meat processing industry, such as cooking, boiling, scalding and pasteurization. In such cases, the waste heat from the extract air, steam and water can be recovered to a large extent via heat exchangers before being temporarily stored and then used to heat the wash water. Compressors, large motors and wastewater used to clean machines and plants are other sources of waste heat.

Replacing energy-intensive processes and technologies with low-cost methods, machines and facilities is a fundamental prerequisite for achieving internationally agreed climate and environmental goals. 
The purification of waste air is a starting point in the meat processing sector. However, the widespread use of thermal and catalytic afterburning emissions from smoking, broiling, frying and roasting facilities consume a lot of energy, are expensive and are harmful to the environment.

Converting to more energy efficient electric filters can reduce energy costs by $80 \%$ compared to thermal afterburning, while significantly reducing emissions of carbon dioxide. Depending on the purification needs, additional modules can be added, for example emission cooling with heat recovery for heating the process water, waste gas purification, UV lighting systems and bio and activated carbon filters. Perfectly adapted, these modules allow a very efficient purification, respectful of the environment, resources, energy and, consequently, a reduction in emissions, while reducing costs.

Machines and plants designed in accordance with hygienic design principles are state-of-the-art and a prerequisite for cleanliness, hygiene and food safety throughout technology and are a prerequisite for cleanliness, hygiene and food safety throughout the meat processing chain.

Hygienic design means fewer surfaces where food, dirt and germs can adhere, saving time, water and energy, as well as detergents and disinfectants for cleaning.

This is especially true in combination with processes such as cleaning-in-place which, although it provides for a defined and time-optimized cleaning, does not realize the full potential of all cleaning processes. The reason is the predetermined cleaning procedures.

Smart cleaning robots represent a whole new approach. Controlled by camera, they adapt the cleaning process to the individual level of contamination of the machine or installation concerned. Their nozzles can be individually controlled and precisely targeted. In addition, the mobile robot also adapts its forward speed to the prevailing conditions. And, thanks to its intelligent software, it avoids spray shadows on even the most complex geometries, dramatically improving cleaning results compared to conventional methods.

Basically, robots have a lower volume flow of about $50 \%$, associated with a $20 \%$ increase in resource efficiency, that is, a $20 \%$ reduction in consumption of water.

The aspects described above are only a fraction of the steps that can be taken to improve energy and resource efficiency. Intelligent sensor technology, control and application software, interconnection of machines and plants, control monitoring and implementation of Industry 4.0 principles offer additional potential for saving time, scarce labor and resources.

\section{Conclusions}

The report of M\&A Agriculture, Food and Beverage Group's Global Food and Beverage Industry shows that the Covid-19 epidemic has had several effects on different areas of the food industry in all regions of the world, with Asia-Pacific and Europe being the most affected. Restaurants, cafes and bars are completely closed in some areas.

Participants of online delivery and takeaway food are able to continue their activities and develop. The packaged food and beverage industry continues to experience an increase in demand, as the shelf-stable food and beverages domain, including dairy products (due to concerns about scarcity and the impact of consumer storage).

The industrial supply chain has been largely affected by the pandemic: For example, the Coca-Cola Company's supply of raw materials from China has been delayed.

As North and South America, Europe, India, and Russia face the second wave of the virus, and now, the world faces the third ones, the number of infections continues to increase, and food safety inspections and restrictions on the outflow of people continue to have a serious impact on the industry.

Today, a large part of the food supply comes from the industrial sector facing multiple challenges. Like all industrial sectors, it must incorporate new environmental and sustainability requirements into its activities. However, they are also undergoing major changes in final consumption and agricultural production. On the one hand, consumers or at least some of them have new expectations for food and its production conditions. On the other hand, developments in agriculture indicate that the methods of 
supplying agricultural raw materials may change. Finally, the company's participation in the dynamics of competition at the national, European or international level raises the issue of medium and longterm competitiveness development.

It is too early to predict whether the GDP growth in the next year will restore the impact of most of the epidemics in Romania, or to prove whether they will be so severe that they will hinder the economy in 2021, it is too early. It is worth mentioning that we should also keep in mind that extremely uncertain forecasts resulting from forecasts should respond to changing pandemic conditions. However, from a comparative perspective, we can identify some important factors that will determine the possible future conditions of the country and the agri-food industry. After the Romanian economy performed relatively well in the first quarter, it contracted $10.5 \%$ of GDP. The current pandemic is long-term stable economic growth. Therefore, the European Commission predicts that GDP will decline by $6.0 \%$ in 2020 and will slightly recover to $4.0 \%$ by the end of 2021 .

\section{References}

Aday, S. and Aday, S.M., 2020. Impact of COVID-19 on the food supply chain. Food Quality and Safety, 4(4), pp.167-180.

Barbut, S., 2020. Meat Industry 4.0: A Distant Future? Animal Frontiers, 10(4), pp.38-47.

CDC (Centers for Disease Control and Prevention). 2020. Agriculture Workers \& Employers, [online] Available at: <https://www.cdc.gov/coronavirus/2019ncov/community/guidance-agriculturalworkers.html $>$ [Accessed on 5 august 2020].

FAO (Food and Agriculture Organization of the United Nations), 2011. Lessons from the world food crisis of 2006-08, Food and Agriculture Organization. [pdf] Available at: $<$ http://www.fao.org/3/i2330e/i2330e04.pdf $>$ [Accessed 2 April 2020].

FAO (Food and Agriculture Organization of the United Nations), WHO (World Health Organization), 2020a. COVID-19 and Food Safety: Guid-ance for food businesses: Interim guidance. [pdf] Available at: $<$ http://www.fao.org/3/ca8660en/CA8660EN.pdf $>$ [Accessed 17 April 2020].

FAO (Food and Agriculture Organization of the United Nations), 2020b. Adjusting business models to sustain agri-food enterprises during COVID-19. [pdf] Available at: $<$ http://www.fao.org/3/ca8996en/CA8996EN.pdf> [Accessed 15 May 2020].

Hobbs, J.E., 2021. The Covid-19 pandemic and meat supply chains, Meat Science, [online] Available at: $<$ https://doi.org/10.1016/j.meatsci.2021.108459 $>$ [Accessed on 1 march 2021].

IPES (The International Panel of Experts on Sustainable Food System), 2020. COVID-19 and the crisis in food systems: Symptoms, causes, and potential solutions. [pdf] Available at: $<\mathrm{http}: / / \mathrm{www}$.ipesfood.org/_img/upload/files/COVID-19_CommuniqueEN.pdf> [Accessed 17 April 2020].

Peretti, J.M., 2020. Editorial. Question(s) de management, 29(3), pp.11-12.

Peretti, J.M., Autissier, D. and Besseyre des Horts, C.H., 2020. Changement de Crise. Les organisations à l'épreuve du Covid19. Paris: MA Editions-ESKA. 